\title{
DEHOUVE Danièle, Offrandes et sacrifices en \\ Mésoamérique
}

\section{Claude-François Baudez}

\section{OpenEdition}

\section{Journals}

Édition électronique

URL : https://journals.openedition.org/jsa/10033

DOI : 10.4000/jsa. 10033

ISSN : 1957-7842

\section{Éditeur}

Société des américanistes

\section{Édition imprimée}

Date de publication : 15 juillet 2008

Pagination : 285-287

ISSN : 0037-9174

\section{Référence électronique}

Claude-François Baudez, "DEHouve Danièle, Offrandes et sacrifices en Mésoamérique », Journal de la Société des américanistes [En ligne], 94-1 | 2008, mis en ligne le 25 juillet 2008, consulté le 02 septembre 2022. URL : http://journals.openedition.org/jsa/10033 ; DOI : https://doi.org/10.4000/jsa. 10033

Ce document a été généré automatiquement le 2 septembre 2022

Tous droits réservés 


\title{
DEHOUVE Danièle, Offrandes et sacrifices en Mésoamérique
}

\author{
Claude-François Baudez
}

\section{RÉFÉRENCE}

DEHOUVE Danièle, Offrandes et sacrifices en Mésoamérique, Riveneuve éditions, Paris, 2007, 260 p. + X p. de pl. coul., bibl., ill., cartes, fig., photos

1 Le propos de l'ouvrage de Danièle Dehouve est de «montrer que c'est le même type d'acte rituel qui est désigné tantôt comme sacrifice, et tantôt comme offrande, car il comprend conjointement ces deux aspects» (p. 6). Ces derniers sont en effet réunis dans le dépôt rituel, pratique que l'auteur a étudiée de 2000 à 2006 chez les Tlapanèques de l'État du Guerrero, en particulier dans le municipe de Zacatepec qui comprend une cinquantaine de villages de 200 à 600 habitants. Le pouvoir politique est exercé par un comisario et son équipe, responsables du bien-être de la communauté et s'occupant également d'activités rituelles avec l'aide d'un spécialiste appelé xiña, "grand-père ». Le dépôt rituel, partie de toute cérémonie, est exécuté tout au long de l'année selon le calendrier cérémoniel. Les dépôts sont exécutés au centre du village ou à sa périphérie, au cimetière, dans les montagnes, les grottes, les rivières et les sources.

2 Le dépôt rituel a pour but de « demander l'année ", à savoir la pluie, la santé, la force, le pouvoir politique, etc. Il est constitué de divers niveaux superposés. Le premier qui représente la base ou la "natte » du dépôt consiste en grandes feuilles de palmes ou de fougères en nombre compté. Viennent ensuite divers objets végétaux, tous en nombre compté : faisceaux de petites palmes, colliers de fleurs, rouleaux et guirlandes de feuilles, mèches de fils de coton. Tous ces objets construisent le siège de la puissance invoquée et son image. L'invitation s'achève par la présentation de dons : un collier de fleurs pour orner le cou de la puissance, des bougies qui représentent un cadeau de lumière, un animal sacrifié qui incarne la nourriture et la boisson offertes à l'invité divin, une poudre métallique qui représente l'argent. Un discours fait d'évocations et de "prières » 
accompagne la déposition; l'officiant fait correspondre le dépôt d'un objet et l'énoncé d'une phrase. En somme, le dépôt rituel est la représentation figurative de l'invitation faite à la puissance invoquée, qui peut être le Feu, la Terre, la Source, la Montagne, les défunts, etc. La structure de l'invitation est la même en toute occasion rituelle, mais les animaux sacrifiés varient suivant le type de dépôt et son destinataire.

Dehouve présente et analyse le symbolisme des objets par leur forme (longiligne qui renvoie au corps humain, circulaire qui complète la forme précédente), leur nombre (où le système vicésimal a complètement disparu), le matériau (feuilles, fleurs, coton, écorce, copal), les couleurs et les parfums. Elle insiste sur les techniques utilisées dans le processus d'assimilation; pour lier le sort de l'homme au contenu du dépôt rituel et à ce qu'il représente, on se sert du souffle, de la proximité par des ligatures, de l'imitation. Comme Hocart (cité p. 218) l'a bien montré, l'acte rituel agit sur les choses au moyen d'équivalences et la pensée rituelle donne une grande importance à la recherche des ressemblances.

On peut faire d'autres lectures du dépôt rituel, en particulier celle d'une re-création du monde; on y découvre également des aspects divinatoires. La polysémie est générale, qu'elle concerne les épisodes du rituel, les objets eux-mêmes et leurs destinataires; elle est cependant très tributaire du contexte.

D'autres sociétés mésoaméricaines contemporaines pratiquent le dépôt rituel. Au tout début $\mathrm{du} \mathrm{xx}^{\mathrm{e}}$ siècle, Lumholtz avait décrit ce rite chez les Huichol. On le trouve bien représenté dans la Huasteca, avec des variantes, comme l'utilisation de poupées de bois et de papier découpé.

Les descriptions et analyses de Danièle Dehouve ont une incidence remarquable sur l'étude du rituel précolombien. L'auteur confirme l'existence, signalée par Nowotny, de dépôts composés d'objets comptés, décrits par l'image et l'écriture dans le Codex Fejérváry-Mayer. Les récentes découvertes de dépôts rituels, accompagnant les diverses phases de construction de la pyramide de la Lune à Teotihuacan, sont tout à fait comparables aux dépôts tlapanèques : ils combinent des dépôts d'objets symboliques par leur matériau, leur forme, leur fonction, etc. et des sacrifices humains et animaux, suivant des configurations orientées. La déposition de ces éléments était, si l'on en croit les exemples donnés dans l'ouvrage, accompagnée de discours.

7 Les dépôts stratifiés (type A) du Grand Temple de Tenochtitlan, étudiés par López Luján, utilisent aussi des objets symboliques pour recréer le monde et finissent avec des sacrifices. Certains dépôts mayas du Classique Ancien de Tikal leur sont comparables.

Dans les dépôts rituels tlapanèques, les sacrifices de poulets, mais surtout ceux de chats et de chiens, éclairent l'importante question de la transmission de l'énergie de la victime aux sacrifiants et aux puissances auxquelles le sacrifice est offert. Les trois aspects de cette énergie, le cœur, le sang et le souffle, doivent être " forts et chauds ». Une longue agonie - discrètement favorisée - est la manifestation de ces qualités requises.

9 L'ouvrage de Danièle Dehouve me paraît un outil indispensable aux ethnologues et archéologues mésoaméricanistes qui souhaitent comprendre les dépôts rituels, que ceuxci soient appelés dépôts de fondation, caches ou offrandes. Il m'est impossible cependant de suivre l'auteur quand celle-ci étend le modèle tlapanèque du dépôt rituel à tous les dépôts passés et présents mésoaméricains. Beaucoup d'entre eux, et la majorité même, sont des offrandes non accompagnées de sacrifices ; beaucoup de sacrifices - comme ceux qui ponctuaient les fêtes mensuelles des Aztèques - ne sont pas obligatoirement 
accompagnés d'offrandes. Enfin, il y a offrandes et offrandes, qui diffèrent dans le mode de déposition et dans la qualité (c'est-à-dire avec une charge symbolique plus ou moins forte) des objets déposés. L'auteur accuse, à mon avis à tort, ses collègues qui ont étudié le sacrifice humain « de l'avoir isolé de ses contextes cérémoniels... n'accordant aucune attention au dépôt concomitant d'objets» (p.9). Je ne crois pas que le sacrifice mésoaméricain doive "être considéré comme un simple épisode du rite dont il fait partie - le dépôt » (p. 10).

10 Ces extrapolations, qui me paraissent abusives, ne compromettent pas pour autant la valeur et l'intérêt de cette étude dans laquelle le présent éclaire le passé de façon éclatante.

\section{AUTEURS}

\section{CLAUDE-FRANÇOIS BAUDEZ}

Directeur de recherche honoraire au CNRS 